\title{
DINÂMICA DA PAISAGEM NO ENTORNO DA RESEX MARINHA DE SÃO JOÃO DA PONTA/PA: UTILIZAÇÃO DE MÉTRICAS E GEOPROCESSAMENTO
}

\author{
Wellingtton Augusto Andrade Fernandes \\ Universidade Federal do Pará, Núcleo de Altos Estudos Amazônicos, Belém, PA, Brasil \\ Coordenador do Laboratório de Análises Espaciais - LAENA \\ wfernandes@ufpa.br \\ Márcia Aparecida da Silva Pimentel \\ Universidade Federal do Pará, Faculdade de Geografia e Cartografia, Belém, PA, Brasil \\ Professora do Programa de Pós-graduação em Geografia - PPGEO \\ mapimentel@ufpa.br
}

\begin{abstract}
RESUMO
Localizada na zona costeira do Pará, a RESEX Marinha de São João da Ponta foi criada para preservar importantes áreas de manguezais e garantir que as comunidades tradicionais de extrativistas que residem em sua Zona de Amortecimento (ZA) possam viver de forma sustentável. No que concerne a gestão desta Unidade de Conservação, a ZA tem a função de proteger os recursos ecossistêmicos, reduzindo a pressão das atividades humanas, principalmente ligadas ao crescimento da agricultura e da área urbana, formas de uso que ao longo do tempo vem contribuindo para a diminuição das áreas de vegetação, (floresta ombrófila densa aluvial e do manguezal). Neste trabalho, objetivou-se avaliar a dinâmica da paisagem na ZA, entre os períodos de 2010 e 2018. Foram utilizadas ferramentas de geoprocessamento na obtenção de informações espaciais referentes às mudanças na paisagem através da análise multitemporal de uso da terra e de métricas de paisagem. Constatou-se que no período analisado as maiores pressões sofridas na ZA estão relacionadas ao aumento das geoclasses agricultura e área urbana, relacionados com a melhoria da infraestrutura de transporte rodoviário e com o aumento da população no município. Em relação às métricas de área $(C A)$ que corresponde à área ocupada por determinada classe e o percentual da área da mancha (PP), os índices de área apontaram para diminuição de área de vegetação (CA) de 51.246,72 para 55.777,75 hectares, principalmente para fragmentos entre 5 a 10 ha e de $10<100$ que diminuíram (PP) de $1,11 \%$ para $0,65 \%$ e de $5,71 \%$ para $3,31 \%$, respectivamente, resultando na perda de áreas de vegetação. Apresenta-se por fim, o Projeto Monitoramento Orbital de Zonas de Amortecimento em Unidades de Conservação (MOZAUC) como uma proposta para o desenvolvimento de ações em favor de redução do desmatamento.
\end{abstract}

Palavras-chave: Ecologia da Paisagem. Geoprocessamento. Reserva Extrativista. Resex Marinha de São João da Ponta. Geografia Ambiental.

\section{LANDSCAPE'S DYNAMICS IN THE SURROUNDINGS OF THE MARINE OF SÃO JOÃO DA PONTA/PA'S RESEX: UTILIZATION OF GEOPROCESSING METRICS} \begin{abstract}
The RESEX Marine of São João da Ponta, alongside Pará's coastline, was created to preserve important areas of mangrove and to ensure that traditional communities that reside inside its Buffer Zone (BZ) can live in a sustainable way. Concerning management of this Area of Protection, the BZ has the function to protect environmental resources from human activities such as agriculture and the growth of urban areas - both responsible for the decrease of natural areas (mangrove and dense ombrophilous forests). In this paper we aim to evaluate the dynamics of the BZ' landscapes between 2010-2018. We utilize geoprocessing tools to obtain spatial data concerning the changes in the landscape by way of multitemporal analysis of land usage and landscape's metrics. We confirm that in the aforementioned time span the biggest pressure put on BZ areas comes from the increasing agriculture and growth of urban areas - related to better infrastructure in transports and population growth. When it comes to area metrics (CA) corresponding to areas occupied by one of these activities and the percentage of stained area (PP), the rates point to the decrease of natural areas (CA) - from 51.246,72 to $55.777,75$ hectares, mainly for fragments between $5-10$ ha and of $10<100$ that decreased (PP) from 1,11\% to $0,65 \%$ and from $5,71 \%$ to $3,31 \%$, which results in the loss of natural areas. As a result of our observations, we present the Project of Orbital Monitoring of Buffer Zones in Conservation Units as a way to implement actions to reduce deforestation.
\end{abstract}

Keywords: Landscape Ecology. Geoprocessing. Extractive Reserve. RESEX Marine of São João da Ponta. Environmental Geography

$\begin{array}{lllll}\text { Caminhos de Geografia } & \text { Uberlândia } & \text { v. 20, n. } 72 \quad \text { Dez/2019 } & \text { p. 326-344 } & \text { Página } 326\end{array}$




\section{INTRODUÇÃO}

O avanço na utilização dos recursos naturais a partir da ampliação da indústria, da agricultura, do extrativismo e da expansão urbana são atores chaves para compreender a dinâmica da paisagem de modo global (PASSOS, 2013). Tais atividades econômicas apropriam-se desordenadamente de áreas compostas por florestas e corpos d'água, utilizando-se desses e de outros recursos naturais, além da sua capacidade mínima de regeneração muitas vezes, necessitando da intervenção humana para sua recuperação, mesmo que de forma parcial.

As preocupações relacionadas com a proteção da bio/geodiversidade tomam proporções internacionais fortemente a partir da década de 80 do século XX, principalmente pautadas por duas questões em especial, a extinção de espécies em massa e as descobertas de usos e aplicações da biodiversidade como matéria prima da biotecnologia. Ainda fazendo referência ao tema, tornou-se cada vez maior a importância das florestas tropicais, visto que possuem cerca de metade das espécies mundiais, constantemente ameaçadas pela ação humana com destaque para o aumento na taxa de desmatamento a nível global, resultando no aumentando consideravelmente do número de fragmentos florestais na paisagem (CASTRO JÚNIOR et al., 2009).

Ao analisar o modo de produção e consumo vigente, tornar-se possível apontar mudanças significativas na paisagem, responsáveis direta e indiretamente por desordens de cunho ambiental, que resultam em danos ao meio ambiente, muitas vezes irreversíveis. Tais danos ao meio ambiente são responsáveis por significativas mudanças na paisagem, o estudo dessa dinâmica pode ser potencializado se analisado e quantificado a luz da ciência geográfica (ROSA, 2005).

O estudo da dinâmica da paisagem é primordial para a identificação de mudanças dos recursos do território, principalmente, relacionados ao aumento dos fragmentos de áreas florestadas. Através das métricas de paisagem aplicadas aos dados de uso e cobertura da terra, tornar-se possível analisar espacialmente a distribuição dos fragmentos de floresta e suas conectividades, possibilitando avaliar a eficiência da Zona de Amortecimento (ZA) na salvaguarda das Unidades de Conservação (UC) por meio da quantificação dos fragmentos em determinado período (MORAES et al., 2015).

É através do prisma quantitativo geográfico com foco no estudo de fragmentos de vegetação em escala multitemporal que possibilita inferir determinadas análises sobre a dinâmica da paisagem, não apenas na área da UC, mas também em sua ZA onde são observadas significativas mudanças no que tange a mudança da paisagem através do mapeamento dos fragmentos de vegetação em diferentes períodos.

A principal importância das ZA em UC é justamente a proteção da unidade e do seu entorno no que concerne à gestão dos recursos naturais de forma sustentável, objetivando salvaguardar a unidade de atividades humanas desordenadas no território. No caso especificamente da ZA da RESEX Marinha de São João da Ponta essas desordens estão ligadas principalmente ao crescimento da agricultura e da expansão da área urbana em detrimento da diminuição das áreas de floresta ombrófila densa aluvial e do manguezal.

Dentre as tipologias de UC de uso sustentável e proteção integral, priorizou-se o estudo sobre a RESEX Marinha de São João da Ponta. As Reservas Extrativistas (RESEX) Marinhas são UC da categoria de uso sustentável, tendo como missão proteger uma importante formação de manguezais no litoral do Brasil e as comunidades tradicionais que vivem no entorno dessas unidades (ICMBio, 2010).

No Estado do Pará essas unidades se destacam, sobretudo, em função do extrativismo do caranguejo, estas unidades possuem conselhos deliberativos que são responsáveis pelas tomadas de decisão, principalmente relacionadas à gestão dos recursos naturais locais (BRASIL, 2000). $\mathrm{Na}$ mesorregião nordeste paraense estão situadas em locais estratégicos para a proteção de importantes áreas de ecossistemas de manguezal. A RESEX Marinha de São João da Ponta foi criada no ano de 2002, sob a gestão do Instituto Chico Mendes de Conservação da Biodiversidade (ICMBio), em virtude de ser uma UC a nível federal.

Na busca de metodologias sobre a dinâmica da paisagem no âmbito da ciência geográfica, a utilização do geoprocessamento contribuiu na obtenção de informações espaciais fundamentais às análises referentes às mudanças na paisagem através da análise multitemporal de uso da terra e das métricas de paisagem. Tais resultados, expressos em mapas georeferenciados representam ganhos significativos, por exemplo, na mensuração de classes de uso e cobertura da terra e na quantificação de índices de paisagem advindos das métricas de paisagem (MOREIRA, 2011; LANG e BLASCHKE, 2009).

$\begin{array}{llllll}\text { Caminhos de Geografia } & \text { Uberlândia } & \text { v. 20, n. } 72 & \text { Dez/2019 } & \text { p. 326-344 Página } 327\end{array}$


A investigação em relação à dinâmica da paisagem na ZA da RESEX Marinha de São João da Ponta por meio da análise do uso e cobertura da terra, e por fim com as métricas de paisagem, possibilitam ponderar sobre as mudanças e suas conectividades no período analisado de 2010 e 2018. Defendese que esse recorte permite avaliar a eficácia na criação da RESEX, e seu papel na proteção dos recursos naturais presentes na zona costeira paraense, com destaque às áreas de vegetação de mangue, ecossistema costeiro de singular importância pelos serviços ambientais e atividade socioeconômica.

A escolha do recorte temporal utilizado nas análises que corresponde aos anos de 2010 e 2018 tem como marco o processo de implantação e pavimentação asfáltica da rodovia estadual PA-375 ocorrida no início de 2010 no município de São João da Ponta, juntamente com a alteração da legislação sobre ZA em UC sem plano de manejo que passa de uma faixa de dez para três quilômetros ocorridos no mesmo ano em razão da resolução CONAMA no 428/2010 (CONAMA, 2010). A implantação da rodovia foi responsável por significativas mudanças na paisagem no entorno da RESEX analisada, visto que no período inicial de execução de tal empreendimento houve registro de embargo no entorno da RESEX Marinha de São João da Ponta pelo órgão gestor da unidade (ICMBio, 2017).

Entende-se, então, que há uma lacuna no que concerne ao objeto de pesquisa. Este refere como problemática a ZA na RESEX Marinha de São João da Ponta, sendo esta uma temática pouco discutida, uma vez que na maioria dos casos as análises ficam restritas ao interior da UC, negligenciando o estudo do entorno dessas unidades (VIO, 2001; MORAES et al., 2015). O estudo busca apresenta novas perspectivas a respeito dos estudos com ênfase nas ZA de UC ainda sem plano de manejo.

Além disso, a RESEX Marinha de São João da Ponta ainda não possui plano de manejo. Nessa perspectiva, a discussão sobre a temática é profunda, pois nessas áreas encontram-se numerosos problemas ligados a pressão dos usos da terra com destaque para inúmeros conflitos rurais e urbanos. Além da proteção biológica, essas áreas são imprescindíveis para a proteção das comunidades tradicionais que habitam o entorno dessas unidades e que utilizam de seus recursos naturais para sua subsistência.

Para minimizar a falta do plano de manejo da RESEX Marinha de São João da Ponta anualmente é elaborado um plano de uso pela gestão da unidade. Segundo o Decreto no 4.340/2002 em seu artigo $\mathrm{n}^{\circ} 15$ "A partir da criação de cada unidade de conservação e até que seja estabelecido o plano de manejo, devem ser formalizadas e implementadas ações de proteção e fiscalização" (BRASIL, 2002). Neste contexto, tornar-se relevante a investigação sobre o referido tema para expor a magnitude da utilização do geoprocessamento como instrumento facilitador no estudo da dinâmica da paisagem a partir do uso da terra e suas métricas, proporcionando o constante monitoramento dos recursos naturais, potencializando a conservação e fiscalização dessas áreas de significativa importância de ordem ambiental, social e cultural.

Nesse cenário, surgem as seguintes indagações em relação aos respectivos problemas. Como o estudo da dinâmica da paisagem no entorno da RESEX Marinha de São João da Ponta pode contribuir para a gestão da unidade diagnosticando a evolução de processos naturais e antropogênicos? Quais são os usos da terra que exercem pressão sobre a UC nesse período localizados na ZA? Existe uma alteração na conectividade dos ecossistemas na área de estudo que possa garantir sua preservação analisando o período de 2010 e 2018 ? Quais mudanças significativas ocorrem na ZA desta unidade com a alteração das faixas previstas na Resolução do Conselho Nacional do Meio Ambiente (CONAMA) no 428/2010?

A referida pesquisa busca analisar a dinâmica da paisagem na zona de amortecimento da RESEX Marinha de São João da Ponta no recorte temporal dos anos de 2010 e 2018. Igualmente, busca-se: Identificar o uso e cobertura da terra através de dados de sensores remotos de alta resolução nos anos de 2010 e 2018; demonstrar através das métricas de paisagem (landscape metrics) as conectividades entre os ecossistemas e avaliar a eficiência da ZA, considerando a mudança nas faixas de dez para três quilômetros, respectivamente, em função da resolução do CONAMA no 428/2010.

Através do conhecimento geográfico aplicado ao estudo da dinâmica da paisagem a partir da utilização do geoprocessamento e métricas de paisagem é possível mensurar as mudanças no que tange a utilização dos recursos naturais em UC e principalmente em suas ZA. Visto que devido à ausência de delimitação dessas zonas nos planos de manejo das unidades, acaba resultando no enfraquecendo da fiscalização no entorno das UC e concomitantemente atingindo as comunidades tradicionais que habitam e utilizam-se dos recursos naturais.

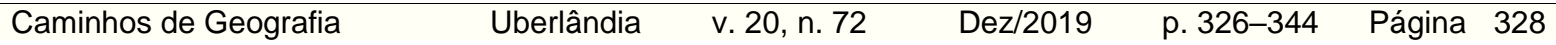




\section{MATERIAIS E MÉTODOS}

\section{ÁREA DE ESTUDO}

O município de São João da Ponta está localizado no estado do Pará na região norte do país, na mesorregião nordeste paraense, na microrregião do salgado, em relação as cartas SA-22-X-B-VI-4 e SA-23-V-A-IV-3, limitando-se ao norte com o município de São Caetano de Odivelas, ao sul com o município de Terra Alta, a leste novamente com município de São Caetano de Odivelas, a oeste com o município de Curuçá. São João da Ponta foi criado no ano de 1995, através do desmembramento do município vizinho de São Caetano de Odivelas, o município é banhado pelos rios mocajuba e mojuim, sua economia está ligada diretamente ao extrativismo (IBGE, 2016; RODRIGUES, 2013; DSG, 2014).

Criada pelo decreto federal s/n de 13 de dezembro de 2002, a RESEX Marinha de São João da Ponta é uma UC do grupo de uso sustentável, que visa proteger a bio/geodiversidade local presente na zona costeira do Pará (BRASIL, 2002). A referida RESEX possui uma área de 3.409,44 hectares, formada por grandes áreas de predomínio do ecossistema manguezal e bioma marinho costeiro, possuindo inquestionável diversidade em recursos naturais característicos da região amazônica, com destaque para o Ucides cordatus, conhecido popularmente como caranguejo-uçá (ICMBio, 2018).

É no referido município que está localizada a RESEX Marinha de São João da Ponta, entre as coordenadas geográficas $0^{\circ} 47^{\prime} 20^{\prime \prime}$ e $0^{\circ} 51^{\prime} 10^{\prime \prime}$ de Latitude Sul e $48^{\circ} 1^{\prime} 12^{\prime \prime}$ e $47^{\circ} 55^{\prime} 20^{\prime \prime}$ de Longitude Oeste (Mapa 1). Caracterizada pelo bioma marinho costeiro, imprescindível na proteção de áreas compostas por manguezais, além da proteção desses recursos a referida RESEX é utilizada por comunidades tradicionais extrativistas que habitam seu entorno (ICMBio, 2010).

Mapa 1 - Localização da RESEX Marinha de São João da Ponta e sua ZA, 2018
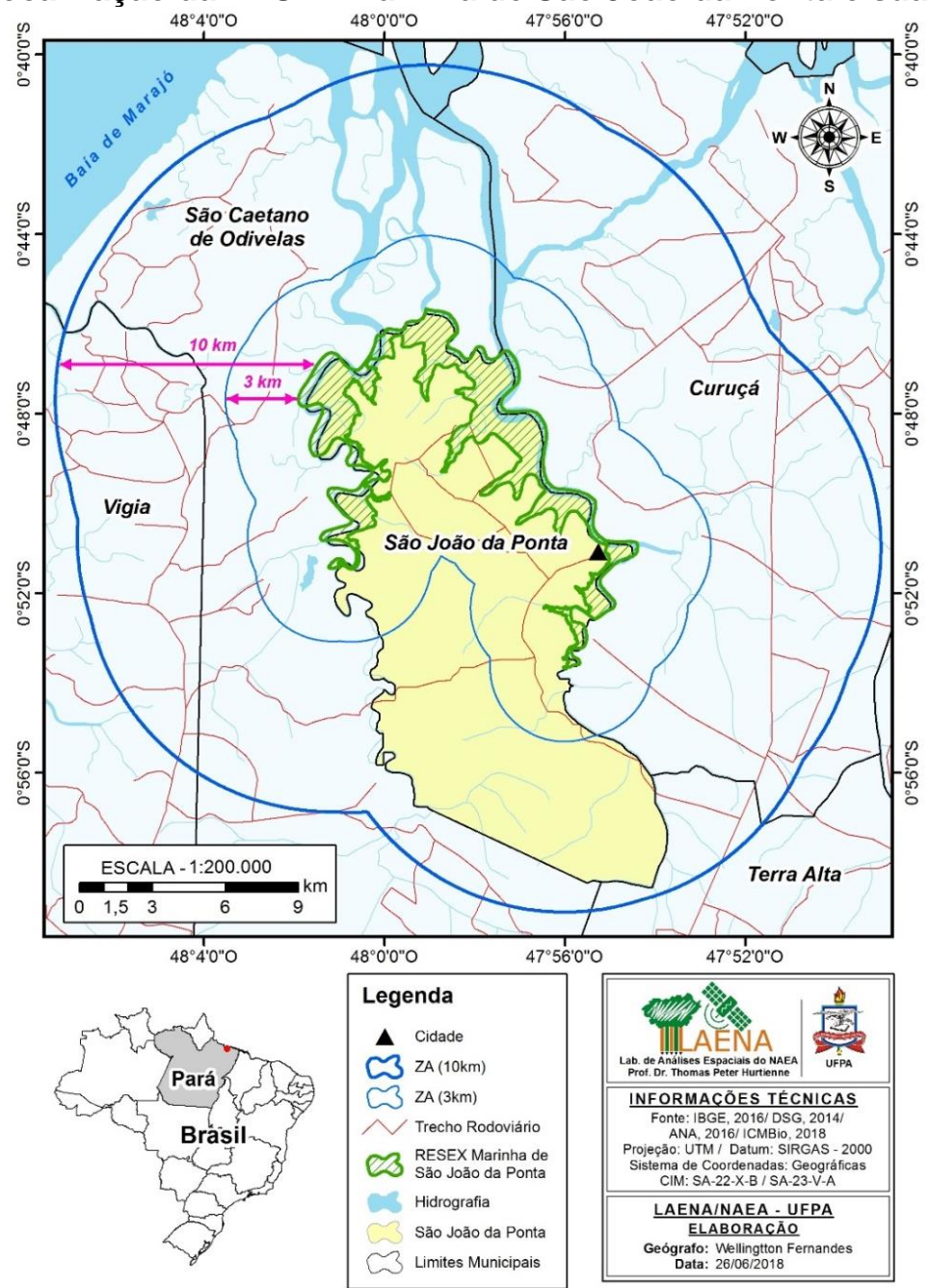


\section{MATERIAIS}

Foram analisados dois dispositivos legais que tratam sobre ZA de UC sem plano de manejo e suas alterações de faixa de dez para três quilômetros, a partir das resoluções do CONAMA no 13/1990 e 428/2010, também foram analisados a resolução CONAMA ${ }^{\circ} 473 / 2015$ e a lei federal $n^{\circ}$ 9.985/2000. Para analisar tal mudança de faixa, utilizou-se como critério a análise da dinâmica da paisagem, relacionados ao geoprocessamento, sensoriamento remoto e métricas de paisagem através do Software de SIG ArcGis 10.3.1 da empresa ESRI e da extensão V-LATE 2.0 beta. (BRASIL, 2000; CONAMA, 1990; 2010; 2015; ESRI, 2015; LANG e TIEDE, 2003).

\section{DADOS CARTOGRAFICOS E METADADOS}

Os dados vetoriais foram fundamentais no processo de leitura espacial relacionada principalmente aos limites municipais, a drenagem, as rodovias, os limites da UC e de sua ZA, o uso e cobertura da terra, localização das cartas internacional ao mundo ao milionésimo (CIM) e das comunidades pertencentes à área de estudo (Tabela 1).

Tabela 1 - Dados cartográficos utilizados (Vetorial)

\begin{tabular}{ccc}
\hline ORIGEM & DADOS UTILIZADOS & ANO \\
ANA & Hidrografia & 2017 \\
DSG & Carta internacional ao mundo ao milionésimo & 2014 \\
IBGE & Limites Municipais, Trecho Rodoviário; Trecho Drenagem; Sedes & 2016 \\
ICMBio & Unidades de Conservação; Embargos & 2018 \\
CAMPO* & Comunidades do entorno da RESEX Marinha de São João da Ponta & 2016 \\
\hline * Os dados foram obtidos em trabalhos de campo com utilização do receptor de sinal GPS de \\
navegação modelo ETREX 30 (Garmin).
\end{tabular}

Os dados matriciais foram divididos em duas cenas, fez se o uso de imagens pertencentes aos sensores High Resolution Geometric (HRS) do satélite SPOT-5 (SEMAS/PA) e do sensor MultiSpectral Instrument (MSI) do satélite SENTINEL-2A (REMOTEPIXEL), sendo a primeira do ano de 2010 e a segunda do ano 2018, conforme (Tabela 2).

Tabela 2 - Dados cartográficos utilizados (Matricial)

\begin{tabular}{ccc}
\hline SENSOR/SATÉLITE & Órbita/Ponto & Data \\
\hline HRG/SPOT-5 & $703-351$ & $06 / 07 / 2010$ \\
MSI/SENTINEL-2A & $22 \mathrm{MHE}$ & $25 / 06 / 2018$ \\
\hline
\end{tabular}

Fonte: SEMAS/PA e REMOTEPIXEL.

A imagem HRG/SPOT-5 foi disponibilizada pela Secretaria Estadual de Meio Ambiente e Sustentabilidade do Pará - SEMAS/PA, e pelo site canadense REMOTEPIXEL referente à imagem $\mathrm{MSI} / S E N T I N E L-2 A$. Em função das semelhanças em relação à resolução espacial e temporal, e também do vasto acervo de imagens que ocorreu a escolha da utilização dos referidos satélites de sensoriamento remoto SPOT-5 e SENTINEL-2A para o estudo do uso e cobertura da terra na RESEX Marinha de São João da Ponta, conforme (Tabela 3).

Para Silva et al. (2018), as imagens Sentinel-2A representam a evolução das análises em estudos que tratam sobre paisagem, visto que contemplam maior qualidade e precisão na observação dessas fisionomias. 
Tabela 3 - Características dos sensores utilizados

\begin{tabular}{ccc}
\hline CARACTERÍSTICA & SPOT-5 & SENTINEL-2A \\
Lançamento & 2002 & 2015 \\
Situação & Desativado em 2015 & Ativo \\
Sensor & HRG (High Resolution & MSI (Multi-Spectral \\
Resolução Espacial & Geometric) & 10 m (MUL) \\
Resolução temporal & 2,5 m (PAN) & 10 dias \\
Resolução Espectral & 26 dias & 4 Bandas \\
Resolução Radiométrica & 5 Bandas & 12 bits \\
\hline
\end{tabular}

\section{PARÂMETROS CARTOGRAFICOS UTILIZADOS}

Os mapas foram desenvolvidos no plano do sistema de coordenadas geográficas e Datum horizontal SIRGAS 2000 (Sistema de Referência Geocêntrico para as Américas), em relação às folhas da carta Internacional ao Mundo ao milionésimo: SA-22-X-B-VI-2, SA-22-X-B-VI-4, SA-23-V-A-IV-1 e SA-23-VA-IV-3 em escala cartográfica de 1:50.000. Na medida em que a resolução do IBGE $n^{\circ}$ 1/2005 torna obrigatório o uso do SIRGAS-2000 como novo sistema de referência geodésico para o Sistema Geodésico Brasileiro (SGB) e para o Sistema Cartográfico Nacional (SCN), a partir de 25 de fevereiro de 2015, não sendo aceito outro sistema de referência (IBGE, 2015)

Optou-se pela utilização do programa ArcGis (Arcmap) 10.3.1 para a manipulação dos dados georreferenciados (vetorial e matricial), criação do Banco de Dados Geográfico (BDG), classificação de uso e cobertura da terra, execução das métricas de paisagem e por fim na construção dos projetos cartográficos. A utilização de sistemas de informações geográficas tem um significativo histórico de utilização no planejamento da paisagem e do meio ambiente a nível global, a exemplo da empresa ESRI que segundo Lang e Blaschke (2009, p. 45) é referência mundial em inúmeros projetos de pesquisa e suas aplicações na proteção e conservação da natureza.

Os produtos cartográficos apresentados foram desenvolvidos no Laboratório de Análises Espaciais Prof. Dr. Thomas Peter Hurtienne (LAENA), localizado no Núcleo de Altos Estudos Amazônicos (NAEA), da Universidade Federal do Pará (UFPA).

\section{MÉTODOS}

A metodologia empregada busca avaliar os instrumentos legais que tratam da mudança na faixa da ZA de UC sem plano de manejo, demonstrando como tais alterações fragilizam a proteção das unidades. A condução do estudo sobre a temática foi realizada por meio da revisão bibliográfica sobre a temática, das análises de uso e cobertura da terra e métricas da paisagem, expressas em mapas, tabelas e figuras. Foram seguidas as seguintes etapas (Figura 1).

1Etapa: Após a pesquisa bibliográfica e o levantamento cartográfico. Antes de iniciar a análise da paisagem foi fundamental determinar a escala cartográfica utilizada, visto seu alto grau de importância teórico-metodológica nos estudos da paisagem (BERTRAND, 2004). O que auxiliou sobremaneira no processo de interpretação visual dos fenômenos estudados, visto que a ampliação da escala melhora a acuidade visual, proporcionando ganhos significativos às análises, principalmente por se tratar de dados coletados por sensores remotos em plataformas orbitais (MOREIRA, 2011). A escala empregada para mapear o uso e cobertura da terra e para as análises espaciais foi de 1:50.000, mediante o cálculo da escala adequada (IBGE, 2013), resultante da divisão da resolução espacial do sensor utilizado pela acuidade visual humana, representada através da equação:

$$
\text { Escala }=\frac{\text { Resolugăo Espacial }}{\text { Acuidade Visual }}
$$

Resolução Espacial: tamanho mínimo do pixel da imagem.

Acuidade Visual: menor valor de precisão gráfica observável a olho nu (0,2 mm ou 0,0002 m). 
A referida equação matemática foi aplicada as imagens de alta resolução dos sensores HRG e MSI, pertencentes respectivamente aos satélites SPOT-5 e SENTINEL-2A:

$$
\begin{aligned}
& \text { Escala }\left(\text { HRG) }=\frac{2,5 m}{0,0002 m} \quad \Rightarrow \quad 25.000\right. \\
& \text { Escala }(\mathrm{MSI})=\frac{10 \mathrm{~m}}{0.0002 \mathrm{~m}} \quad \Rightarrow \quad 50.000
\end{aligned}
$$

Figura 1 - Etapas da pesquisa

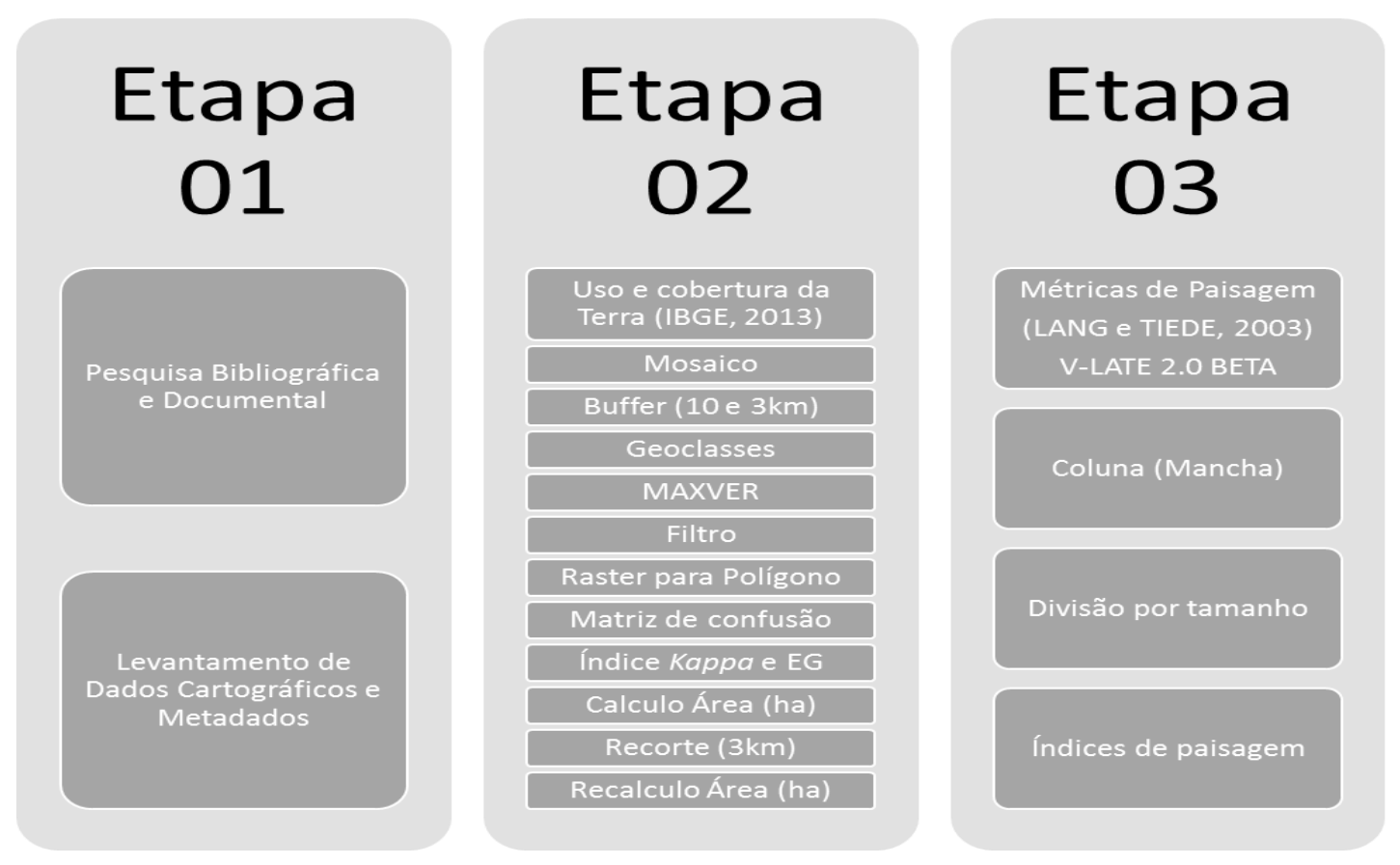

Assim, a escala de trabalho utilizada para mapeamento do uso e cobertura da terra na ZA da RESEX Marinha de São João da Ponta foi de 1:50.000, que é compatível com os dados das imagens dos dois sensores utilizados, como demonstrado pela equação acima.

$2^{\circ}$ Etapa: Os procedimentos de uso e cobertura da terra foram baseados no manual do IBGE de 2013. Iniciou-se com o mosaico das cenas do sensor HRG/SPOT-5 do ano de 2010, ressalta-se que não foi necessário realizar o mosaico da imagem do sensor MSI/SENTINEL-2A do ano de 2018, pois a área de estudo encontrava-se em apenas uma única cena desse sensor. Após a realização do mosaico foi executado o buffer de dez e três quilômetros no entorno do shapefile da RESEX Marinha de São João da Ponta em acordo com as resoluções CONAMA n 13/1990 e 428/2010.

Em seguida foi definida a geoclasses utilizadas para realização da classificação supervisionada do tipo máxima verossimilhança (MAXVER), iniciou-se a coleta das amostras das geoclasses: Hidrografia, Vegetação, Agricultura, Área Urbana, Solo Exposto, Nuvem e Sombra para as imagens de 2010 e 2018. Após a classificação, objetivando potencializar as análises de uso e cobertura da terra, juntamente com os aspectos visuais nos mapas, optou-se pela utilização do filtro predominante (ESRI, 2015) que foi responsável pela eliminação de pixels isolados encontrados na classificação supervisionada MAXVER. A filtragem potencializa o aspecto visual dos mapas sem intervir de maneira significativa na acuidade do mapeamento (PERREIRA; GUIMARÃES, 2018).

Ao termino da classificação os dados resultantes em formato raster foram transformados para dados vetoriais do tipo polígono através da ferramenta Raster para Polígono (ESRI, 2015). Para medir o grau de acurácia dos dados gerados pela classificação foi criada uma matriz de confusão para apontar a qualidade dos dados, medidos através do índice kappa e da exatidão global (ANDERSON et al., 1979; KRIPPENDORFF, 2004; WENDPAP, 2013; KESTRING et al., 2015). Para utilização da

Caminhos de Geografia $\quad$ Uberlândia $\quad$ v. 20, n. $72 \quad$ Dez/2019 $\quad$ p. 326-344 Página 332


matriz de confusão foram criados 50 pontos para cada classe mapeada, ao total foram obtidos 600 pontos de controle (CONGALTON, 1991).

Ao termino da verificação de confiabilidade da classificação MAXVER através da matriz de confusão, foi calculada a área em hectares dos dois arquivos shapefile resultantes da classificação das imagens de 2010 e 2018 que corresponde a ZA de dez quilômetros. Para finalizar essa etapa foi realizado o recorte (ESRI, 2015) do arquivo vetorial de uso e cobertura da terra em dez quilômetros em relação ao buffer de três quilômetros no entorno da RESEX Marinha de São João da Ponta, novamente para os anos de 2010 e 2018, conforme apontado pela resolução CONAMA $n^{\circ}$ 428/2010 e foram recalculadas as áreas do novo arquivo vetorial de três quilômetros tendo em vista o recorte.

Para manipulação dos dados vetoriais e matriciais; criação do banco de dados geográfico; processamento dos dados georreferenciados e elaboração dos mapas foi utilizado o software de Sistema de Informação Geográficas (SIG) ArcGis (arcmap) versão 10.3.1 (ESRI, 2015).

$3^{\circ}$ Etapa: As análises das métricas da paisagem (landscape metrics) foram realizadas a partir da extensão do software ArcGis denominada V-LATE 2.0 beta (Vector-based landscape analysis tools extension) desenvolvida por Lang e Tiede (2003), possibilitando medir a estrutura da paisagem através de índices da paisagem. A referida extensão permitiu quantificar as métricas de paisagem relacionadas a de área, tamanho, borda, forma, retalhamento e proximidade em relação aos fragmentos da geoclasse vegetação (LANG e TIEDE, 2003; LANG e BLASCHKE, 2009).

Visando potencializar as análises foi criada a coluna (Mancha) na tabela de atributos dos quatro arquivos vetoriais gerados classificação supervisionada MAXVER em relação a ZA de 3 e 10km cada um para os anos de 2010 e 2018, totalizando quatro arquivos. A coluna mancha foi dividida por tamanho, na qual: < 5 (muito pequeno); 5 - 10 (pequeno); 10 - 100 (médio) e > 100 (grande).

Em seguida foram geradas as métricas de paisagem de área: CA (Área de todas as manchas da classe) e PP (Percentual da mancha); de tamanho: MPS (Tamanho médio da mancha), NP (Número de manchas) e PSSD (Desvio padrão do tamanho da mancha); de borda: TE (Soma das bordas) e ED (Densidade das bordas); de forma: MPAR (Razão média do perímetro pela área) e MFRACT (Dimensão fractal média); de retalhamento: DIVISION (Índice de Divisão da Paisagem); e de proximidade: MPI (Índice de proximidade média) (MCGARIGAL e MARKS, 1995; LANG e TIEDE, 2003; LANG e BLASCHKE, 2009).

A partir do emprego dos referidos materiais e métodos com a apresentação da área de estudo, da pesquisa bibliográfica e documental, dos dados cartográficos e metadados, dos parâmetros empregados, do uso e cobertura da terra e das métricas da paisagem, envolvidos na pesquisa. Buscou-se realizar uma discussão a partir do desdobramento dos resultados alcançados pela referida pesquisa.

\section{GEOPROCESSAMENTO E O USO DA TERRA}

O Brasil possui uma grande carência de informações apropriadas para tomadas de decisões que envolvem os aspectos problemáticos na área urbana, rural e, sobretudo ambiental num país de dimensão continental, o geoprocessamento visa potencializar as ações de tomadas de decisão, baseado em tecnologias relativamente de baixo custo (CÂMARA e DAVIS, 2001).

Para Câmara e Ortiz (1998) o principal objetivo do geoprocessamento "é fornecer ferramentas computacionais para que diferentes analistas determinem as evoluções espacial e temporal de um fenômeno geográfico e as inter-relações entre diferentes fenômenos". Segundo Fitz (2008a, p. 108) geoprocessamento é definido como:

Técnica que, utilizando um SIG, busca a realização de levantamentos, análises e cruzamentos de informação georreferenciadas, visando à realização do planejamento, manejo e/ou gerenciamento de um espaço especifico, apoia-se na cartografia digital para realizar essa manipulação de dados.

Para Moreira (2011, p. 202) "Geoprocessamento é um conjunto de tecnologias voltadas à coleta e ao tratamento de informações espaciais para um objeto especifico, ou seja, uma informação atrelada a um atributo geográfico". Fazer uso do geoprocessamento necessariamente implica na utilização de um sistema de informação geográfica (SIG) para a gestão de dados georreferenciados.

A base estruturante do SIG está alicerçada na análise espacial de dados referenciados espacialmente, conforme apontado por Vitte (2007, p. 104) "o coração de um sistema de informações

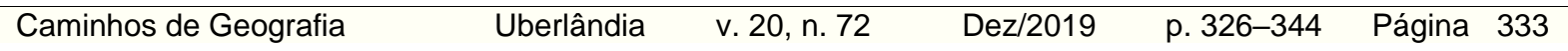


geográfico é a análise espacial". Segundo (IBGE, 2013, p. 157), "a estrutura de um SIG para o tema uso da terra pode apoiar os órgãos públicos a entidades privadas na tomada de decisão em níveis de intervenção regionais".

De modo a diferenciar o conceito de geoprocessamento e SIG, o primeiro é um conceito mais abrangente e representa qualquer tipo de processamento de dados georreferenciados, enquanto o segundo processa dados gráficos e não gráficos (alfanuméricos) com ênfase em análises espaciais e modelagens de superfícies (ROSA, 2009; MOREIRA, 2011). Objetivando diferenciar geoprocessamento de SIG é necessário frisar que:

As atividades que envolvem o geoprocessamento são executadas por sistemas específicos para cada aplicação. Esses sistemas são mais comumente tratados como sistemas de informação geográfica (SIG). Em outras palavras é a utilização de técnicas matemáticas e computacionais para tratar dados obtidos de objetos ou fenômenos geograficamente identificados ou extrair informações desses objetos ou fenômenos quando eles são observados por um sistema sensor (MOREIRA, 2011, p. 202).

As informações relacionadas ao uso e cobertura da terra são imprescindíveis para subsidiar a adoção de determinadas atitudes no que se refere à gestão territorial (FLORENZANO, 2008). Sendo fundamental às análises quantitativas, constituindo-se como importante instrumento para o planejamento e orientação às tomadas de decisão (IBGE, 2013).

Em determinadas situações a aquisição de imagens de uma única data, acaba não sendo suficiente para mapear o uso e cobertura da terra, na perspectiva da análise multitemporal. Sendo necessária a utilização de imagens coletadas em mais de uma data, por exemplo, como ocorre em estudos de expansão urbana, da agricultura e do desmatamento na Amazônia com uso de dados orbitais. Conforme Moreira (2011, p. 271), "A abordagem multitemporal não restringe apenas o uso de imagens de um mesmo sensor".

$\mathrm{Na}$ execução das análises espaciais foram elencados alguns fatores para a escolha das imagens utilizadas, como a resolução espacial e temporal. A primeira está relacionada com a capacidade do sensor instalado em plataformas orbitais de discriminar determinados objetos em função do tamanho real em relação ao tamanho do pixel na imagem, a segunda característica corresponde à frequência de imageamento sobre a mesma área (FLORENZANO, 2011).

O Banco de Dados Geográfico (BDG) se diferencia dos demais bancos de dados por armazenar dados referentes à localização geográfica dos eventos. Se tratando de pesquisas relacionadas à análise de dados espaciais é fundamental a construção do BDG, tendo em vista seu potencial em relação à agregação de valores aos estudos ambientais relacionados à consulta e a análise espacial. Auxiliando em grande medida na representação de dados geográficos em ambiente computacional, na busca de respostas para melhor entender o espaço geográfico e suas respectivas mudanças. Em sensoriamento remoto o BDG é estruturado por projetos, contendo informações espaciais e não espaciais (MOREIRA, 2011, p. 207-208).

O BDG utilizado foi organizado a partir de dados vetoriais e matriciais, o primeiro relacionado a arquivos shapefile no formato (.shp) e último pertinente aos arquivos no formato (.tif). A estrutura matricial é representada por uma matriz composta por linhas e colunas, já a representação vetorial é representada por pontos, linhas e polígonos (MOREIRA, 2011).

O processo de classificação de imagens pode ser subdividido basicamente em dois tipos a supervisionada e não supervisionada. A classificação supervisionada utilizada no desenvolvimento desse trabalho detecta tipos específicos de classes, necessitando do conhecimento prévio da área estudada pelo interprete. Já a classificação não supervisionada, consiste na generalização de todas as categorias de cobertura da terra existente na imagem de forma automática, sem o conhecimento prévio da área objeto de estudo, ou seja, não se tem a realização de trabalhos de campo (ROSA, 2009; MOREIRA, 2011).

$\mathrm{Na}$ classificação das imagens seja supervisionada ou não-supervisionada são identificadas as classes ou geoclasses de informação, e passam por um sistema de processamento estatístico de suas respectivas refletâncias em cada pixel da imagem. Em relação a sua homogeneidade, através da análise da assinatura espectral de cada alvo imageado.

A classificação supervisionada do tipo MAXVER inicia-se com a determinação do número de classes a ser utilizada, posteriormente da se início a atribuição de valores aos pixels, ou seja, determinando

$\begin{array}{lllll}\text { Caminhos de Geografia } & \text { Uberlândia } & \text { v. 20, n. } 72 & \text { Dez/2019 } & \text { p. 326-344 Página } 334\end{array}$


quais células representam cada uma das classes de uso e cobertura da terra que se dá a partir de amostras fornecidas pelo analista, nessa fase é imprescindível que as amostras coletadas sejam as mais homogêneas possíveis. O método de classificação MAXVER é inquestionável, o mais utilizado no processo de classificação supervisionada nos estudos relacionados ao sensoriamento remoto. Visto que, esse tipo de classificação permite a identificação de diversas classes de informação, com destaque para a cobertura do solo (ROSA, 2009; MOREIRA, 2011).

De fato as habilidades e experiências do analista responsável pela interpretação das imagens são fundamentais ao bom andamento do trabalho. Segundo Moreira (2011, p. 274) a experiência do interprete deve ser pautada em três fatores: o conhecimento do problema, da técnica e da região a ser estudada, os quais são fundamentais as análises de dados orbitais em sensoriamento remoto. Independente da utilização de dados de sensoriamento remoto como instrumento facilitador à compreensão do espaço geográfico, não se pode desconsiderar a necessidade da realização de trabalhos de campo, os quais proporcionam a confirmação da veracidade dos dados analisados.

Após análise dos dados de uso e cobertura da terra na ZA da RESEX Marinha de São João da Ponta, constatou-se que no período analisado de 2010 e 2018 as maiores pressões sofridas na ZA da referida unidade estão relacionadas ao aumento das geoclasses agricultura e área urbana, relacionados principalmente com a melhoria da infraestrutura de transporte rodoviário e com o aumento da população no município, potencializados com a mudança da legislação ambiental em 2010 da faixa de ZA de UC sem plano de manejo de dez para três quilômetros.

\section{DEMONSTRAÇÃO DAS MÉTRICAS DA PAISAGEM E SUAS CONECTIVIDADES}

Tratando-se da perda da biodiversidade a nível global é notável destacar o papel da fragmentação da vegetação nesse processo, principalmente relacionado ao isolamento de manchas de floresta que resultam na perda da conectividade. E a gestão permanente dessas áreas é fundamental na redução do processo de insularização desses fragmentos. É justamente através das análises de uso da terra e das métricas da paisagem que é possível avaliar e monitorar quantitativamente as pressões diretamente exercidas na paisagem e no território, demonstrando a capacidade de gestão, grau de isolamento, conectividades e a perda da biodiversidade das UC e suas ZA (GONÇALVES et al., 2009).

Tendo em vista o processo de análise espacial da paisagem a partir de imagens de sensores remoto, optou-se por utilizar a distância de amortecimento (buffer distance) que consiste na designação de uma faixa de distância em volta de uma feição ponto, linha ou polígono (LANG e BLASCHKE, 2009, p. 66). Foram feitas análises em relação à distância de amortecimento entorno do polígono da RESEX Marinha de São João da Ponta (ICMBio, 2018) nas faixas de dez e três quilômetros, de acordo com as normas ambientais, respectivamente em função das resoluções do CONAMA $n^{\circ}$ $13 / 1990$ e 428/2010.

Estudar o espaço geográfico e os aspectos ambientais nele presentes pressupõe de imediato uma gama de informações e conhecimentos que podem ser analisados de maneira mais eficiente com a utilização de tecnologias (FITZ, 2008b). As métricas da paisagem (landscape metrics), o geoprocessamento e o sensoriamento remoto são importantes tecnologias empregadas nos estudos geográficos, principalmente no que tange ao emprego de métodos quantitativos.

Os dados relacionados às métricas de paisagem utilizadas foram geradas através da extensão $V$ LATE 2.0 beta (Vector-based landscape analysis tools extension), responsável pela quantificação das métricas de paisagem aplicadas as manchas da geoclasse vegetação, no que tange a: área, forma, densidade, tamanho, borda e proximidade (LANG e TIEDE, 2003; LANG e BLASCHKE, 2009). A extensão $V$-LATE 2.0 beta desenvolvida por Lang e Tiede (2003) é uma valiosa ferramenta de análise da paisagem baseada em vetores, fornecendo um conjunto de métricas empregadas em investigações ecológicas, principalmente relacionados à análise estrutural de padrões, imprescindíveis na avaliação estrutural da paisagem. Segundo Mascarenhas e Biondi (2012) a análise da estrutura da paisagem, em função de sua matriz e dos fragmentos como componentes estruturantes, são eficazes subsídios na verificação da funcionalidade do uso da terra em UC e suas ZA.

Avaliando os dados de métricas de paisagem relacionadas à área, tamanho, borda, forma, retalhamento e proximidade no que tange aos fragmentos de vegetação localizados na ZA de dez quilômetros (CONAMA, 1990). No entorno da RESEX Marinha de São João da Ponta, em relação aos anos 2010 e 2018, constatou-se que:

$\begin{array}{llllll}\text { Caminhos de Geografia } & \text { Uberlândia } & \text { v. 20, n. } 72 & \text { Dez/2019 } & \text { p. 326-344 Página } 335\end{array}$


Em relação às métricas de área $(C A)$ que corresponde à área ocupada por determinada classe e o percentual da área da mancha (PP), os índices de área apontaram para diminuição de área de vegetação $(C A)$ de $51.246,72$ para $55.777,75$ hectares, principalmente para fragmentos entre 5 a 10 ha e de $10<100$ que diminuíram (PP) de $1,11 \%$ para $0,65 \%$ e de $5,71 \%$ para $3,31 \%$, respectivamente, resultando na perda de áreas de vegetação.

Analisando as métricas de tamanho (MPS) que corresponde ao tamanho médio dos fragmentos, (NP) o número de fragmentos e (PSSD) o desvio padrão do tamanho dos fragmentos. Os índices de tamanho revelaram que o tamanho médio dos fragmentos (MPS) diminuiu de 4,87 ha para 1,03 ha, principalmente em relação aos fragmentos de vegetação menores que 5 hectares, juntamente com o aumento do (NP) de 10.519 para 54.075 que sinaliza o aumento da fragmentação, ratificado pelo aumento do (PSSD) de 124,04 para 130,36, visto que o aumento nos valores de área apresentam fragmentos com tamanho muito acima da média (MCGARIGAL e MARKS, 1995). Resultando no aumento da fragmentação das áreas de vegetação, principalmente em fragmentos menores que 5 ha (LANG e BLASCHKE, 2009).

Considerando as métricas de borda (TE) total de bordas e (ED) densidade de bordas. Os índices de borda indicam um acelerado aumento do efeito de borda, visto que houve aumento do (TE) de 687,32 $\mathrm{m}$ para $1.477,07 \mathrm{~m}$, ratificado pelo aumento da (ED) que passou de $134,12 \%$ para $264,81 \%$, na medida em que o maior valor expõe maior efeito de borda (LANG e BLASCHKE, 2009).

Analisando as métricas de forma (MPAR) índice médio de forma e (MFRACT) dimensão fractal média. Os índices de forma indicam um aumento do (MPAR) de 0,309 para 0,775 quanto mais próximo de 1 maior é o grau de irregularidade de forma dos fragmentos, o aumento do (MFRACT) de 1,53 para 1,88 quanto maior o valor do mais recortado e complexas são os fragmentos da paisagem (LANG e BLASCHKE, 2009).

Avaliando a métrica de retalhamento (DIVISION) que mede o índice de divisão da paisagem. $O$ referido índice de retalhamento indicam um alto grau de fragmentação para os fragmentos menores que 5 ha (DIVISION) 99,9\% e 99,96\%, visto que quanto maior o resultado, maior o grau de fragmentação (LANG e BLASCHKE, 2009).

Analisando as métricas de paisagem pautadas em relação aos índices de área, tamanho, borda, forma, retalhamento e proximidade para os fragmentos de vegetação localizados na ZA de três quilômetros (CONAMA, 2010) no entorno da RESEX Marinha de São João da Ponta em relação aos anos 2010 e 2018, constatou-se que:

Em relação às métricas de área $(\mathrm{CA})$ e $(\mathrm{PP})$. Os índices de área apontaram para diminuição de área de vegetação $(C A)$ de $15.733,45$ para $15.466,591$ ha, principalmente para fragmentos de $10<100$ que diminuíram (PP) de 5,47\% para 3,27\%, resultando também na perda de áreas de vegetação. Analisando as métricas de tamanho (MPS), (NP) e (PSSD). Os índices de tamanho revelaram uma diminuição do (MPS) de 6,61 ha para 1,51 ha, juntamente com o aumento do (NP) de 2.380 para 11.052 que sinaliza o aumento da fragmentação.

Considerando as métricas de borda (TE) e (ED). Os índices de borda indicam um acelerado aumento do efeito de borda, visto que houve aumento do (TE) de $1.876 .352,54 \mathrm{~m}$ para $3.807 .427,76 \mathrm{~m}$, ratificado pelo aumento da (ED) que passou de $119,26 \%$ para $227,95 \%$. Analisando as métricas de forma (MPAR) e (MFRACT). Os índices de forma indicam um aumento do (MPAR) de 0,42 para 0,84 resultando na elevação da irregularidade de forma dos fragmentos, o aumento do (MFRACT) de 1,54 para 1,87 .

Avaliando a métrica de retalhamento (DIVISION). O índice de retalhamento indica um alto grau de fragmentação para os fragmentos menores que 5 ha (DIVISION) $99,5 \%$ e $99,8 \%$, visto que quanto maior o resultado, maior o grau de fragmentação (LANG e BLASCHKE, 2009).

Considerando a métrica de proximidade (MPI). O índice de proximidade indica um aumento da fragmentação, principalmente entre os fragmentos de 5 a 10 hectares, aumentando o (MPI) de 0,82 para 186,67 na medida em que o índice quantifica a proximidade em um contexto espacial de um fragmento em relação aos seus vizinhos (MCGARIGAL e MARKS, 1995).

Em relação ao número de machas (NP) dos fragmentos de vegetação encontrados na paisagem da ZA de $10 \mathrm{~km}$ no entorno da RESEX Marinha de São João da Ponta em 2010 e 2018, observou-se que em 2010 havia um total de 54.075 e em 2018 houve diminuição para 10.519. Em relação à ZA de

$\begin{array}{llllll}\text { Caminhos de Geografia } & \text { Uberlândia } & \text { v. 20, n. } 72 & \text { Dez/2019 } & \text { p. 326-344 Página } 336\end{array}$


$3 \mathrm{~km}$, observou-se que em 2010 havia um total de 11.052 manchas que diminuíram em 2018 para 2.380. Juntamente com a diminuição de outros índices de paisagem relacionados à área, como a área total das manchas (CA) e do percentual de área da mancha (PP), observou-se que principalmente os fragmentos de vegetação menores que cinco hectares ( $>10$ ha) tem maior tendência ao retalhamento, ou seja, são áreas prioritárias às politicas públicas de proteção ambiental. Concordando com Pütz et al. (2011) o maior número de manchas de fragmentos de vegetação isolados estão em fragmentos menores que 25 ha. A distribuição espacial dos fragmentos com áreas abaixo de dez hectares na paisagem encontram-se espalhadas na paisagem, principalmente nos limites da ZA (Mapa 2).

Mapa 2- Métricas de paisagem (manchas)

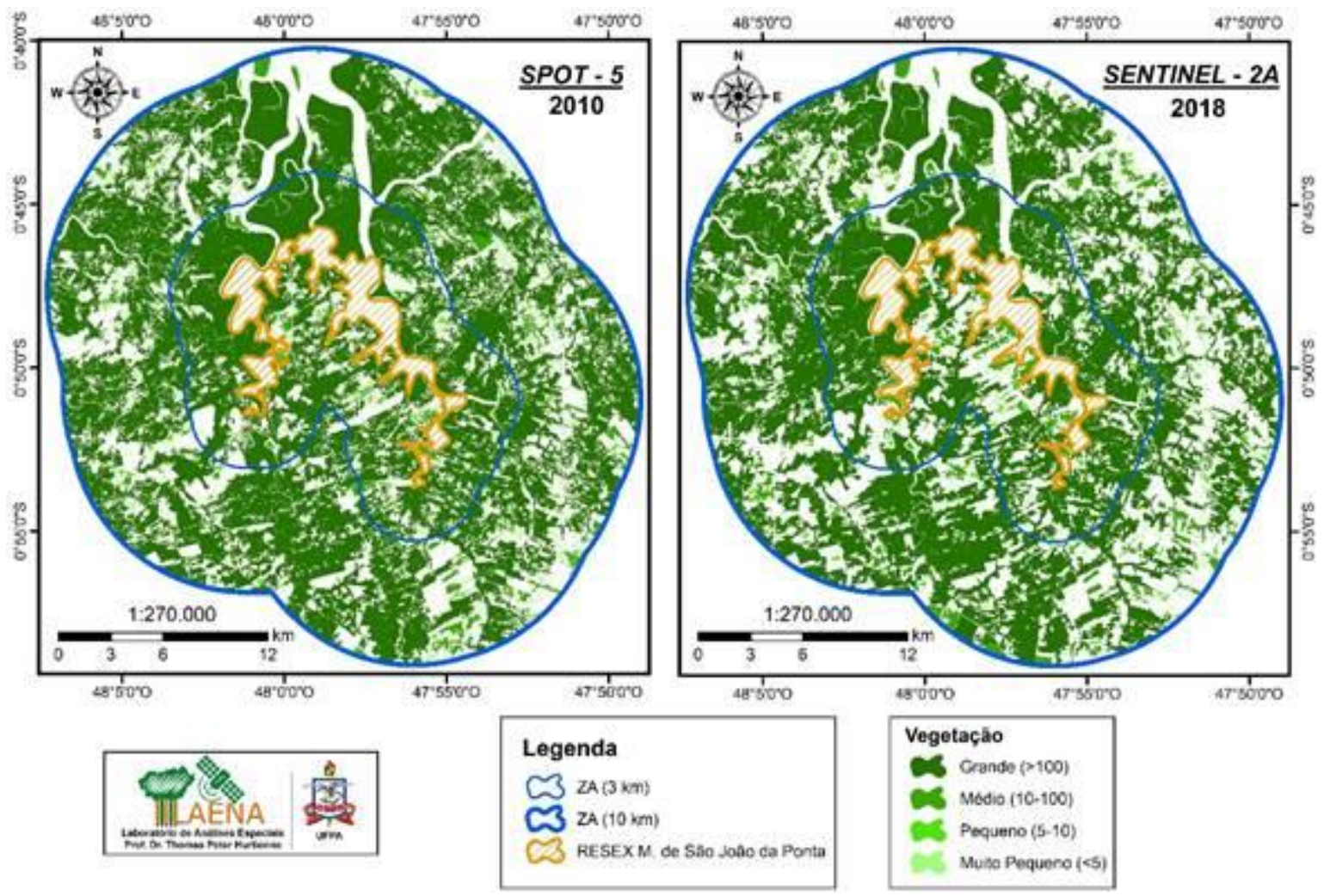

As perturbações originadas pela ação antrópica intensificam sobremaneira a fragmentação natural da paisagem, resultando em implicações ambientais graves, muitas vezes de difícil reparação. Os fragmentos mais isolados possuem função de stepping stones, verdadeiros trampolins ecológicos entre diferentes habitats fragmentados (METZGER, 2001; SILVA et al., 2015). Determinadas espécies cruzam pequenas clareiras para se conectar a outros fragmentos e a matriz, porém são impedidas pela presença de extensas áreas degradas (LAURANCE et al., 2002). Os problemas de ordem ambiental são claramente de caráter social, visto que surgem da sociedade e não da natureza (MARTINELLI, 2018).

O efeito de borda potencializa sobremaneira a fragmentação de áreas vegetadas, para Pütz et al. (2011) a fragmentação ocorre principalmente em áreas florestadas menores que 25 hectares. Como consequência da diminuição nas dimensões individuais dos fragmentos de vegetação decorrentes do efeito de borda, observa-se a suavização das formas complexas que pode conduzir à extinção de parte dos fragmentos, visto que "o efeito de borda atua sobre os fragmentos e suas irregularidades, transformando figuras geométricas complexas em superfícies que tendem à circularidade". (SILVA et al., 2015).

Determinadas características dos fragmentos de vegetação como área, tamanho, forma, retalhamento e proximidade com outros fragmentos tem influência em incontáveis processos ecológicos, por exemplo, mortalidade, migração e colonização de fauna e flora. A riqueza de espécies é uma razão

$\begin{array}{lllll}\text { Caminhos de Geografia } & \text { Uberlândia } & \text { v. 20, n. } 72 & \text { Dez/2019 } & \text { p. 326-344 Página } 337\end{array}$


diretamente proporcional ao tamanho do fragmento, ou seja, áreas de vegetação intactas possuem maior número de espécies por unidade de área se comparados aos fragmentos. Na medida em que muitas espécies grandes mamíferos, primatas, aves e insetos são altamente sensíveis à fragmentação e ao isolamento, determinadas espécies necessitam de áreas extensas, minimamente acima de cem hectares (>100 ha) (LAURANCE et al., 2002).

Segundo MORAES et al. (2015) a diminuição de áreas florestadas aumenta consideravelmente a presença de fragmentos na paisagem cada vez menores, diminuindo sobremaneira a conectividade dessas áreas, contribuindo para o isolamento das UC e acelerando o efeito de borda ${ }^{1}$. Principalmente nas ZA que são áreas mais vulneráveis, criadas no entorno das UC com o propósito de minimizar impactos negativos, dentre os quais se encontra o efeito de borda (BRASIL, 2000). Vale ressaltar que boa parte dos estudos sobre UC não tratam sobre seu entorno, ou seja, ainda pouco se discuti sobre as ZA, peculiaridade da pesquisa vigente que busca subsidiar no que tange a gestão da ZA no plano de manejo.

É valido destacar que existe uma notável diversidade de efeitos de borda em florestas tropicais fragmentadas, tais efeitos podem alterar gradientes físicos, distribuição de espécies e acentuados processos ecológicos e ecossistêmicos, transformações na paisagem, facilmente observadas no bioma amazônico. Alguns efeitos próximos às bordas de fragmentos de vegetação como mudanças no microclima que são reflexo da redução da umidade, aumento da luz solar e acentuada amplitude de temperatura, adentram até 60 metros no interior dos fragmentos, afetando negativamente espécies adaptadas a interiores escuros e de alta umidade, redução da decomposição, dificuldade de germinação de sementes e suscetível a queimadas, resultando no aumento da vulnerabilidade das bordas (LAURANCE et al., 2002).

Analisando os índices de paisagem gerados, evidenciou-se que os fragmentos menores e médios de vegetação tem uma grande importância em relação à conectividade, visto sua funcionalidade como stepping stones por toda a área de estudo. Com o aumento do efeito de borda muitos fragmentos menores que cinco hectares deixam de existir, acarretando perda da conectividade, daí a necessidade de monitoramentos dos fragmentos mais frágeis, além de auxiliar na recuperação.

Avaliando a mudança na legislação ambiental no que tange a delimitação da ZA, constatou-se que com a diminuição da faixa de dez para três quilômetros, tornou o entorno das UC ainda mais frágil em relação à fragmentação e isolamento de manchas de vegetação influenciado pelo efeito de borda.

\section{CONSIDERAÇÕES FINAIS}

Os estudos da dinâmica da paisagem aliado as análises multitemporais de uso e cobertura da terra e da ecologia de paisagem através de seus índices de métricas possibilitam potencializar o monitoramento dos fragmentos/manchas de vegetação no entorno das UC. Auxiliando significativamente à gestão dessas unidades, o estudo da dinâmica da paisagem no entorno da RESEX Marinha de São João da Ponta permitiu diagnosticar a evolução dos processos naturais e antropogênicos através da análise da fragmentação, isolamento e do efeito de borda em relação às manchas de vegetação. Através dos dados de uso da terra é possível desvendar pressões relacionadas a conflitos ambientais e fundiários, principalmente ligados à agricultura do entorno da unidade. Tornando possível avaliar mudanças em determinadas políticas públicas, mensurando a conectividade e fragmentação da vegetação na ZA das UC.

A ZA da RESEX Marinha de São João da Ponta mostrar-se fundamental à salvaguarda de áreas de vegetação no entorno da unidade em detrimento das fortes pressões antropogênicas. Revelando, assim o valor das ZA em UC na preservação e conservação de importantes áreas de vegetação florestal e de manguezal, com destaque para o grande mosaico de fragmentos das RESEX localizadas na zona costeira do estado do Pará.

O estudo contribuiu para o monitoramento dos fragmentos no entorno de UC, colaborando para o fortalecimento da gestão da ZA da RESEX Marinha de São João da Ponta diagnosticando a evolução dos processos naturais e antropogênicos, através da análise do uso e cobertura da terra, posteriormente aliando a aplicação de índices de métricas de paisagem e discutindo a legislação ambiental a respeito da mudança na faixa da ZA em UC sem plano de manejo. Apesar da contribuição desse estudo para a gestão das ZA de RESEX na zona costeira do estado do Pará,

\footnotetext{
1 São modificações nos parâmetros físicos, químicos e biológicos observadas na área de contato do fragmento de vegetação com a matriz circundante (LIMA-RIBEIRO, 2008).

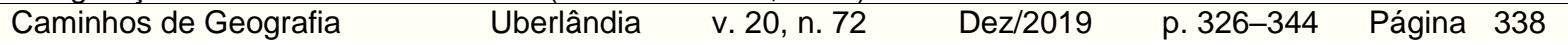


juntamente com a possibilidade de adaptações desse estudo de caso para outras inúmeras UC ainda sem plano de manejo na Amazônia. O estudo ressalta a existência de limitações, como a dificuldade em diferenciar áreas de vegetação florestal das áreas de vegetação de manguezal.

O estudo da dinâmica da paisagem na ZA da RESEX Marinha de São João da Ponta possibilitou concluir que as manchas de fragmentos de vegetação menores que dez hectares ( $>10$ ha) têm maior tendência ao retalhamento e a perda da conectividade, potencializados pela pressão da agricultura sobre as áreas de vegetação. Os fragmentos menores que dez hectares sofrem ainda mais com o efeito de borda, tornando-se necessário potencializar a fiscalização ambiental nessas áreas prioritárias com a criação de políticas públicas de proteção ambiental específica. A diminuição da faixa de ZA no entorno das UC de dez para três quilômetros, culminou no aumento da pressão da agricultura sobre a vegetação, resultando no aumento da fragmentação.

É necessária a implantação de ações efetivas que resultem em projetos e políticas públicas que auxiliem no planejamento e gestão ambiental em ZA de UC, com ênfase às unidades de uso sustentável. Como fruto dessa discussão levantada, propõe-se como ação o desenvolvimento do Projeto Monitoramento Orbital de Zonas de Amortecimento em Unidades de Conservação (MOZAUC) uma cooperação técnica com o ICMBio/São João da Ponta, visto que colabora grandemente para a gestão ambiental e modernização de processos no manejo. Finalmente, o estudo da dinâmica da paisagem no entorno da RESEX Marinha de São João da Ponta contribuiu para a gestão da unidade, pois possibilitou avaliar e monitorar as pressões sobre a bio/geodiversidade local através da análise da dinâmica da paisagem.

\section{AGRADECIMENTOS}

À Gestão do ICMBio em São João da Ponta.

À Associação dos Usuários da Reserva Extrativista Marinha de São João da Ponta (MOCAJUIM).

\section{REFERÊNCIAS}

AGÊNCIA NACIONAL DE ÁGUAS - ANA. Base Hidrográfica (Shapefile) - 2017. Disponível em: $<$ http://metadados.ana.gov.br/geonetwork/srv/pt/main.home?uuid=efd77aa1-3c73-4ca1-9cbc7a2193ea743b>. Acesso em: 04 set. 2017.

ANDERSON, J. R.; HARDY, E. E.; ROACH, J. T.; WITMER. Sistemas de classificação do uso da terra e do revestimento do solo para utilização com dados de sensores remotos. Rio de Janeiro: IBGE, 1979, p. 13-62. Disponível em: <https://biblioteca.ibge.gov.br/visualizacao/livros/liv82180.pdf>. Acesso em: 28 dez. 2018.

ASNER, Gregory P. Cloud cover in Landsat observations of the Brazilian Amazon. International Journal of Remote Sensing, v. 22, n. 18, p. 3855-3862, 2001.

https://doi.org/10.1080/01431160010006926

ALVES, R. J. M.; GONÇALVES, W. G.; GONÇALVES, J. P.; DE L NUNES, G.; SILVA, E. R. M.; MAIA, J. S.; NARVAES, I. S. Análise do Uso e Ocupação do Solo em Marapanim-PA a partir de Dados do Projeto TERRACLASS. HOLOS, 34(1), p. 81-90, 2018. . Disponível em: $<$ https://search.proquest.com/openview/b63cc132a78527fdeca2d7f8a244f933/1?pqorigsite $=$ gscholar\&cbl=1356374 $>$. Acesso em 28 dez. 2018.

BERTRAND, Georges. Paisagem e Geografia Física Global. Esboço Metodológico. Revista RA'E GA. n. 8, p. 141-152. Curitiba: Editora UFPR, 2004. https://doi.org/10.5380/raega.v8i0.3389

BRASIL. Constituição da República Federativa do Brasil de 1988. Disponível em: <http://www.planalto.gov.br/ccivil_03/constituicao/constituicaocompilado.htm>. Acesso em 20 ago. 2017.

Decreto no 6.040, de 07 de fevereiro de 2007. Institui a Política Nacional de Desenvolvimento Sustentável dos Povos e Comunidades Tradicionais. 2007a. Disponível em: <http://www.planalto.gov.br/ccivil_03/_ato2007-2010/2007/Decreto/D6040.htm>. Acesso em: 20 ago. 2017.

Decreto no 4.340, de 22 de agosto de 2002. Regulamenta artigos da Lei no 9.985, de 18 de julho de 2000, que dispõe sobre o Sistema Nacional de Conservação da Natureza - SNUC, e dá outras providências. Disponível em: http://www.planalto.gov.br/ccivil_03/decreto/2002/D4340.htm. Acesso em 20 nov. 2018.

$\begin{array}{lllll}\text { Caminhos de Geografia } & \text { Uberlândia } & \text { v. 20, n. } 72 & \text { Dez/2019 } & \text { p. 326-344 Página } 339\end{array}$


Decreto s. n., de 13 de dezembro de 2002. Cria a Reserva Extrativista de São João da Ponta, no Município de São João da Ponta, no Estado do Pará, e dá outras providências. Brasília, DF: Casa Civil, 2002. Disponível em: <http://www.planalto.gov.br/ccivil_03/DNN/2002/Dnn9775.htm>. Acesso em 20 ago. 2017.

Decreto $s / n^{\circ}$ de 20 de maio de 2005. Dispõe sobre a criação da Reserva Extrativista Marinha de Caeté-Taperaçu, no Município de Bragança, no Estado do Pará, e dá outras providências. Brasília, DF: Casa Civil, 2005. Disponível em: < http://www.planalto.gov.br/ccivil_03/_Ato2004-2006/2005/Dnn/Dnn10531.htm>. Acesso em 20 ago. 2017.

Lei 9.985/2000. Regulamenta o art. 225, § 10, incisos I, II, III e VII da Constituição Federal, institui o Sistema Nacional de Unidades de Conservação da Natureza e dá outras providências. 2000. Disponível em: <http://www.planalto.gov.br/ccivil_03/leis/ L9985.htm>. Acesso em 20 ago. 2017.

CÂMARA, Gilberto; DAVIS, Clodoveu. Introdução ao geoprocessamento. INSTITUTO NACIONAL DE PESQUISAS ESPECIAIS (INPE). Fundamentos de Geoprocessamento. São José dos Campos, v. 1, p. 1-5, 2001.

CÂMARA, Gilberto; ORTIZ, Manoel Jimenez. Sistemas de informação geográfica para aplicações ambientais e cadastrais: uma visão geral. In: Congresso Brasileiro de Engenharia Agrícola. 1998. p. 59-82. Disponível em: <http://www.dpi.inpe.br/geopro/trabalhos/analise.pdf>. Acesso em: 20 de Out. 2017.

CASTRO JUNIOR, Evaristo de; COUTINHO, Bruno Henriques; FREITAS, Leonardo Esteves de. Gestão da biodiversidade e áreas protegidas. In: Unidades de Conservação: Abordagens e Características Geográficas. Orgs. GUERRA, A. J. T. e COELHO, M. C. N. Rio de Janeiro: Editora Bertrand Brasil, p. 25-65, 2009.

CONGALTON, R. G. A Review of Assessing the Accuracy of Classification Remotely Sensed Data. Remote Sensing of Environment, v. 37, p. 35-46, 1991. Disponivel em: <https://www.sciencedirect.com/science/article/abs/pii/003442579190048B >. Acesso em: 28 de dez. 2018. https://doi.org/10.1016/0034-4257(91)90048-B

CONAMA - Conselho Nacional do Meio Ambiente. Resolução № 428, de 17 de Dezembro de 2010. Dispõe, no âmbito do licenciamento ambiental sobre a autorização do órgão responsável pela administração da Unidade de Conservação (UC), de que trata o § 3 do artigo 36 da Lei no 9.985 de 18 de julho de 2000, bem como sobre a ciência do órgão responsável pela administração da UC no caso de licenciamento ambiental de empreendimentos não sujeitos a EIA-RIMA e dá outras providências. Disponível em: <http://www2.mma.gov.br/port/conama/legiabre.cfm?codlegi=641>. Acesso em 20 ago. 2017.

Resolução $n^{\circ} 13$ de 06 de dezembro de 1990. Considerando a necessidade de estabelecer-se, com urgência normas referentes ao entorno das Unidades de Conservação visando a proteção dos ecossistemas ali existentes. Disponível em: <http://www2.mma.gov.br/port/conama/res/res90/res1390.html>. Acesso em jan. 2018.

Resolução no 473 de 11 de dezembro de 2015. Prorroga os prazos previstos no §2º do art. $1^{\circ} \mathrm{e}$ inciso III do art. $5^{\circ}$ da Resolução $\mathrm{n}^{\circ}$ 428, de 17 de dezembro de 2010, que dispõe no âmbito do licenciamento ambiental sobre a autorização do órgão responsável pela administração da Unidade de Conservação (UC). Disponível em: <http://www2.mma.gov.br/port/conama/legiabre.cfm?codlegi=719>. Acesso em jan. 2018.

DIOS, C. B.; MARÇAL, M. S. Legislação ambiental e a gestão de Unidades de Conservação: o caso do Parque Nacional da Restinga de Jurubatiba-RJ. In: Orgs. GUERRA, A. J. T., COELHO, M. C. N. Unidades de Conservação: abordagens e características geográficas. Rio de Janeiro, Bertrand Brasil, p. 173-197, 2009.

Diretoria do Serviço Geográfico do Exército Brasileiro - DSG. 2014. Carta Internacional do Mundo ao Milionésimo do Brasil (Shapefile). Rio grande do Sul. [CD-ROM].

EMBRAPA MONITORAMENTO POR SATÉLITE. Satélites de Monitoramento.

Campinas: Embrapa Monitoramento por Satélite, 2013. Disponível em: <http://www.sat.cnpm.embrapa.br>. Acesso em 22 set. 2017.

$\begin{array}{llllll}\text { Caminhos de Geografia } & \text { Uberlândia } & \text { v. 20, n. } 72 & \text { Dez/2019 } & \text { p. 326-344 Página } 340\end{array}$


ESA - European Space Agency. GMES Sentinel-2 Mission Requirements Document. European Space Agency, 2010. Disponível em: <http://esamultimedia.esa.int/docs/GMES/Sentinel-2_MRD.pdf>. Acesso em 20 dez. 2017.

Introducing Sentinel-2. European Space Agency, 2016. Disponível em:

$<$ http://www.esa.int/Our_Activities/Observing_the_Earth/Copernicus/Sentinel-2/Introducing_Sentinel2>. Acesso em 20 dez. 2017.

ESRI. Software ArcGIS® versão 10.3.1. Imagem, 2015.

FERREIRA, Leandro Valle; VENTICINQUE, Eduardo; ALMEIDA, Samuel. O desmatamento na Amazônia e a importância das áreas protegidas. Estudos avançados, v. 19, n. 53, p. 157-166, 2005. https://doi.org/10.1590/S0103-40142005000100010

FITZ, Paulo Roberto. Cartografia básica. (Nova Edição). São Paulo: Oficina de Textos, $2008 \mathrm{.}$.

FITZ, Paulo Roberto. Geoprocessamento sem complicação. São Paulo: Oficina de textos, 2008b.

FLORENZANO, Teresa Gallotti. Iniciação em Sensoriamento Remoto. $3^{\circ}$ edição. São Paulo: Oficina de Textos, 2011.

Geomorfologia: conceitos e tecnologias atuais. Oficina de Textos, 2008.

FORMAN, Richard T.; GODRON, Michel. Landscape ecology. John Wiley \& Sons. New York, v. 4, p. 22-28, 1986.

GANEM, Roseli. Senna. Zonas de amortecimento de unidades de conservação. Brasília: Câmara dos Deputados, 2015. Disponível em: <http://www2.camara.leg.br/atividade-legislativa/estudos-enotas-tecnicas/publicacoes-da-consultoria-legislativa/areas-da-conle/tema14/2015-515-zonas-deamortecimento-de-unidades-de-conservacao-roseli-ganem>. Acesso em 20 dez. 2018.

GARVÃO, Rodrigo Fraga; BAIA, Simone Andrea Lima do Nascimento. Legislação Ambiental: um histórico de desafios e conquistas para as políticas públicas brasileiras. Nova Revista Amazônica, v. 6, n. 2, p. 93-102, 2018. Disponível em:

<https://periodicos.ufpa.br/index.php/nra/article/view/6193/4908>. Acesso em 20 dez. 2018.

GONÇALVES, C. N., Lima, L. H. A., LINTOMEN, B. S., CASELLA, P. D. C., \& BERLINCK, C. N. Zona de amortecimento: criação ou delimitação. Revista Natureza \& Conservação, 7(2), 38-43, 2009.

Disponível em:

<https://www.researchgate.net/profile/Christian_Berlinck/publication/266227674_ZONA_DE_AMORTE CIMENTO_CRIACAO_OU_DELIMITACAO/links/55d49dce08ae43dd17de457d/Z̄ONA-DE-

AMORTECIMENTO-CRIACAO-OU-DELIMITACAO.pdf>. Acesso em 20 nov. 2018.

GOTTMANN, Jean. A evolução do conceito de território. Boletim Campineiro de Geografia, v. 2, n. 3, p. 523-545, 2012.

ICMBIO/IBAMA. Caracterização dos aspectos socioambientais e econômicos da reserva extrativista de São João da ponta e proposta de estudos complementares. Documento Técnico elaborado pelo ICMBio aprovado em Conselho Deliberativo e em análise na Procuradoria Federal Especializada do ICMBio. São João da Ponta: 2010.

ICMBio. Relatório de Gestão 2011. Brasília, DF: Instituto Chico Mendes de Conservação da Biodiversidade - ICMBio/MMA, 2011.

Mapa Temático e Dados Geoestatísticos das Unidades de Conservação Federais (Shapefile) - 2018. Disponível em: <http://www.icmbio.gov.br/portal/geoprocessamentos/51-menuservicos/4004-downloads-mapa-tematico-e-dados-geoestatisticos-das-uc-s>. Acesso em 03 jun. 2018.

Unidades de Conservação - São João da Ponta. Brasília, DF: Instituto Chico Mendes de Conservação da Biodiversidade - ICMBio/MMA [2017]. Disponível em:

<http://www.icmbio.gov.br/portal/unidadesdeconservacao/biomas-brasileiros/marinho/unidades-deconservacao-marinho/2278-resex-de-sao-joao-da-ponta>. Acesso em 03 de jun. 2017.

INSTITUTO BRASILEIRO DE GEOGRAFIA E ESTATÍSTICA. IBGE Cidades: São João da Ponta, Pará. IBGE, 2010 - 2018 (População Estimada). Disponível em:

<https://cidades.ibge.gov.br/xtras/perfil.php?codmun=150746>. Acesso em 20 ago. 2018.

Bases Cartográficas Continuas (Shapefile) - 2016. Disponível em:

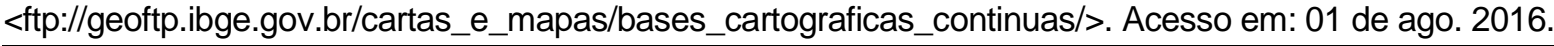

$\begin{array}{lllll}\text { Caminhos de Geografia } & \text { Uberlândia } & \text { v. 20, n. } 72 & \text { Dez/2019 } & \text { p. 326-344 Página } 341\end{array}$


Resolução 01/2015. Define a data de término do período de transição definido na RPR 01/2005 e dá outras providências sobre a transformação entre os referenciais geodésicos adotados no Brasil. Disponível em:

<ftp://geoftp.ibge.gov.br/metodos_e_outros_documentos_de_referencia/normas/rpr_01_2015_sirgas2 000.pdf>. Acesso em 02 out. $201 \overline{8}$.

KESTRING, F. B., GUEDES, L. P., DE BASTIANI, F., \& URIBE-OPAZO, M. A.. Comparação de mapas temáticos de diferentes grades amostrais para a produtividade da soja. Engenharia Agrícola, 35(4), 733-743, 2015. https://doi.org/10.1590/1809-4430-Eng.Agric.v35n4p733-743/2015

KRIPPENDORFF, K. Content analysis: an introduction to its methodology. Beverly Hills: Sage Publications, 2004.

LANDIS, J. Richard; KOCH, Gary G. The measurement of observer agreement for categorical data. Biometrics, p. 159-174, 1977. Disponível em:

<https://www.ncbi.nlm.nih.gov/pubmed/843571?dopt=Abstract>. Acesso em: 20 dez. 2018.

https://doi.org/10.2307/2529310

LANG, Stefan; BLASCHKE, T. Análise da paisagem com SIG. São Paulo, SP: Oficina de Texto, 2009.

LANG, Stefan; TIEDE, Dirk. vLATE Extension für ArcGIS-vektorbasiertes Tool zur quantitativen Landschaftsstrukturanalyse. ESRI Anwenderkonferenz, 2003.

LAURANCE, WILLIAM F.; LOVEJOY, THOMAS. E.; VASCONCELOS, HERALDO. L.; BRUNA, EMILIO. M.; DIDHAM, RAPHAEL. K.; STOUFFER, PHILIP. C.; GASCON, C.; BIERREGAARD, R.; LAURANCE, SUZAN \& SAMPAIO, E. Ecosystem decay of Amazonian forest fragments: a 22-year investigation. Conservation Biology, v. 16, n. 3, p. 605-618, 2002. Disponível em:

<https://onlinelibrary.wiley.com/doi/full/10.1046/j.1523-1739.2002.01025.x>. Acesso em 20 set. 2018. https://doi.org/10.1046/j.1523-1739.2002.01025.x

LESER, H. Landschaftsokologie. Uni Taschenbucher. Stuttgart ,1997.

LIMA, L.A. de S.; NEUMANN, M. R. B.; REATTO, A.; ROIG, H. L. Mapeamento de Solos do Tradicional ao Digital. Planaltina: Embrapa Cerrados, 2013. Disponível em:

$<$ https://www.embrapa.br/busca-de-publicacoes/-/publicacao/1005933/mapeamento-desolos-dotradicional-ao-digital>. Acesso em 10 dez. 2018.

LIMA-RIBEIRO, Matheus de Souza. Efeitos de borda sobre a vegetação e estruturação populacional em fragmentos de Cerradão no Sudoeste Goiano, Brasil. Acta Botânica Brasílica, Belo Horizonte, v. 22, n. 2, p. 535-545, abr./jun. 2008. Disponível em: <>. Acesso em 20 out. 2017. https://doi.org/10.1590/S0102-33062008000200020

MARTINELLI, M. Mapas da Geografia e cartografia temática. São Paulo: Contexto, 2013.

MARTINELLI, M. Cartografia ambiental: um mapa de síntese. Confins. Revue franco-brésilienne de géographie/Revista franco-brasilera de geografia, n. 35, 2018. Disponível em:

$<$ https://journals.openedition.org/confins/13273>. Acesso em 12 dez. 2018.

https://doi.org/10.4000/confins. 13273

MASCARENHAS GRISE, Mayssa; BIONDI, Daniela. Análise da estrutura da paisagem do Parque Nacional do Superagüi-PR e sua zona de amortecimento. Ciência Florestal, v. 22, n. 1, 2012. https://doi.org/10.5902/198050985076

MCGARIGAL, K.; MARKS, B. Fragstats: spatial pattern analysis program for quantifying landscape structure. US Dept. of Agriculture, Forest Service, Pacific Northwest Research Station, 1995. Disponível em: <https://www.fs.fed.us/pnw/pubs/pnw_gtr351.pdf>. Acesso em 18 jan. 2018. https://doi.org/10.2737/PNW-GTR-351

MEDEIROS, J. S. de.; CÂMARA, G. Geoprocessamento para projetos ambientais. In: Câmara, G.; Davis, C.; Monteiro, A. M. V. Introdução à ciência da geoinformação. São José dos Campos: INPE, 2001.

METZGER, Jean Paul. O que é ecologia de paisagens? Biota Neotropica 1: 1-9. 2001. Disponível em: <http://www.biotaneotropica.org.br/v1n12/pt/fullpaper?bn00701122001+pt>. Acesso em 18 jan. 2018. https://doi.org/10.1590/S1676-06032001000100006 
2010, na região de Ouro Preto-MG. Cerne, 21(2), 301-309, 2015. Disponível em: <https://www.redalyc.org/pdf/744/74441023016.pdf>. Acesso em: 20 set. 2018.

SILVA, Robson Righi da; ALBA, E.; MARCHESAN, J.; ZIEMBOWICZ, M. M.; \& PEREIRA, R. S. Análise da Fragmentação Florestal em Áreas do Bioma Mata Atlântica a Partir de Diferentes Sistemas Sensores. UFRJ: Anuário do Instituto de Geociências, Vol. 41, 2018. Disponível em: <http://www.anuario.igeo.ufrj.br/2018_2/2018_2_390_396.pdf>. Acesso em 03 set. 2018. https://doi.org/10.11137/20182390 396

SIQUEIRA, Mariana Nascimento; CASTRO, Selma Simões; FARIA, Karla Maria Silva. Geografia e ecologia da paisagem: pontos para discussão. Soc. \& Nat., Uberlândia, 25 (3), 2013. Disponível em: <http://www.scielo.br/pdf/sn/v25n3/v25n3a09.pdf.> Acesso em: 18 jan. 2018. https://doi.org/10.1590/S1982-45132013000300009

VERDUM, Roberto; VIEIRA, L. de F. dos S.; PINTO, B. F.; SILVA, L. A. P. da. Paisagem: leituras, significados, transformações. Rio Grande do Sul: Editora da UFRGS, 2012.

VIO, A. P. A. Zona de amortecimento e corredores ecológicos. In: BENJAMIN, A. H. Direito ambiental das áreas protegidas - o regime jurídico das Unidades de Conservação. Rio de Janeiro: Forense Universitária, p. 348-360, 2001.

VITTE, Antonio Carlos. Contribuições à história e à epistemologia da geografia. Rio de Janeiro: Bertrand Brasil, 2007.

WENDPAP, Bruna Gabriela. Variabilidade Espacial Utilizando Modelos Geoestatísticos Escalonados e com repetições múltiplas Independentes na Agricultura de Precisão. Dissertação de Mestrado EM Engenharia Agrícola. Cascavel: UNIOESTE, 2013. Disponível em: <http://tede.unioeste.br/bitstream/tede/2608/1/BrunaGabriela.pdf>. Acesso em 10 jan. 2019.

Recebido em: 27/02/2019

Aceito para publicação em: 02/09/2019 